\title{
The politics of female pain: women's citizenship, twilight sleep and the early birth control movement
}

\author{
Lauren Maclvor Thompson ${ }^{1,2}$
}

${ }^{1}$ College of Law, Georgia State University, Atlanta, Georgia, USA

${ }^{2}$ Department of History and Political Science, Georgia State University Perimeter College Alpharetta Campus, Alpharetta, Georgia, USA

\section{Correspondence to}

Dr. Lauren Maclvor Thompson, College of Law, Georgia State University, Atlanta, GA 30302, USA; Imacivor1@gsu.edu

Accepted 3 September 2018 Published Online First 28 September 2018
Check for updates

(c) Author(s) (or their employer(s)) 2019. No commercial re-use. See rights and permissions. Published by BMJ.

To cite: Maclvor Thompson L. Med Humanit 2019:45:67-74.

\section{ABSTRACT}

The medical intervention of 'twilight sleep', or the use of a scopolamine-morphine mixture to anaesthetise labouring women, caused a furore among doctors and early 20th-century feminists. Suffragists and women's rights advocates led the Twilight Sleep Association in a quest to encourage doctors and their female patients to widely embrace the practice. Activists felt the method revolutionised the notoriously dangerous and painful childbirth process for women, touting its benefits as the key to allowing women to control their birth experience at a time when the maternal mortality rate remained high despite medical advances in obstetrics. Yet many physicians attacked the practice as dangerous for patients and their babies and antithetical to the expectations for proper womanhood and motherly duty. Historians of women's health have rightly cited Twilight Sleep as the beginning of the medicalisation and depersonalisation of the childbirth process in the 20th century. This article instead repositions the feminist political arguments for the method as an important precursor for the rhetoric of the early birth control movement, led by Mary Ware Dennett (a former leader in the Twilight Sleep Association) and Margaret Sanger. Both Twilight Sleep and the birth control movement represent a distinct moment in the early 20th century wherein pain was deeply connected to politics and the rhetoric of equal rights. The two reformers emphasised in their publications and appeals to the public the vast social significance of reproductive pain-both physical and psychological. They contended that women's lack of control over both pregnancy and birth represented the greatest hindrance to women's fulfilment of their political rights and a danger to the healthy development of larger society. In their arguments for legal contraception, Dennett and Sanger placed women's pain front and centre as the primary reason for changing a law that hindered women's full participation in the public order.

In October of 1870, women's rights organiser Elizabeth Cady Stanton addressed a crowd on the necessity of transforming the relationship between maternity and pain. For centuries, women's reproductive sufferings were viewed as biblical punishment, based on the verses in Genesis where God tells Eve that as punishment for her sins, 'I will greatly increase your pangs in childbirth; in pain you shall bring forth children'. Instead Stanton told her audience that Genesis was not, in fact, female destiny. She proclaimed, 'Instead of leaving everything in the home to chance, as now, we should apply science and philosophy to our daily life. I should feel that I had not lived in vain, if faith of mine could roll off the soul of woman that dark cloud, that nightmare, that false belief, that all her weaknesses and disabilities are natural, that her sufferings in maternity are a punishment for the sins of Adam and Eve, and teach her...that by obedience to natural law she might secure uninterrupted health and happiness for herself...,1

Stanton's words urged alteration to the institution of marriage to better reflect 'the laws of the universe' that held men and women as equals and placed the concept of alleviating female pain - both psychic and physical-at the heart of women's long struggle for legal and social rights in the United States. Over three decades later, her reference to women's 'sufferings in maternity' (particularly resonant for an audience well aware of the era's abysmal maternal mortality rate) would come into the focus of an expanding feminist movement. Just before World War I, women reformers began championing Twilight Sleep, or the use of scopolamine-morphine in labour, as a key advancement in improving childbirth experiences and outcomes. Some of the activists from the Twilight Sleep movement, including suffragist Mary Ware Dennett who was spurred by her own painful childbirth experiences, would then also join the burgeoning birth control movement. Alongside Margaret Sanger, Dennett contended that both women's maternal suffering and their political disabilities could be eliminated through the legal distribution of contraception.

The historical literature on gender and reproductive pain has traditionally focused on the act of childbirth itself and less on the broader ideological foundations of the movement to legalise contraception. Additionally, there is a wide literature on the history of pain and its management, but more work is needed to address the explicit historical connections between pain and the measures of women's political power. ${ }^{2-5 i}$ The concept and experience of pain itself, as scholars have well noted, is not just 'the result of a biochemical process' but rather a 'cultural and psychosocial event' (Morris, 4). ${ }^{3}$ As Martin Pernick has observed in his study on the use of anaesthesia in surgery in the 19th century, both physicians and the public historically held a 'widely shared belief that different types of people differed in their sensitivity to pain, a doctrine whose implications reached far beyond anesthesia... and played an important... role in such

${ }^{\mathrm{i}}$ For comprehensive histories of pain, see refs. ${ }^{2-5}$ 
diverse areas as feminism, imperialism, abolition, penology, pedagogy, and poetry. This tailoring of prescription to fit the patient, as well as the disease, provoked explicitly political controversy, because it required confronting the conflicting demands of individuality and equality' (Pernick, 6-7). ${ }^{4}$

The history of American obstetrics, gynaecology and female reproduction prior to the emergence of either the Twilight Sleep or birth control movements reveals how conceptions of pain in different populations were deeply raced, classed and gendered. Antebellum physicians such as Dr J Marion Sims, who tested new gynaecological surgical techniques on enslaved women, also believed that black women bore pain more easily, while white women - particularly middle and upper class women-were fragile and far more sensitive ${ }^{67}$ When Dr Bernard Krönig developed the scopaline-morphine protocol of Twilight Sleep, he had in mind the 'theory of the modern woman; not that she is unnatural, but that, on the contrary, to inflict upon her many burdens and sufferings which a cruder type of woman took as a matter of course is unnatural'. He conceptualised that Twilight Sleep would help would help white upper-class women give birth the same way that he had once allegedly seen a 'gypsy-woman who had dropped behind the band to give birth to a child back of a hedge. She had washed he baby in a nearby book and then had run at top speed to catch up with the gypsy-van'. ${ }^{8}$ These medical perceptions of pain underscored and reified existing social and racial divisions.

It is also worth noting that controversies over women's pain in childbirth (and otherwise) continue unabated in today's medical debates about pain relievers. As Joanna Bourke has noted, numerous recent studies have recognised that women, minorities and working-class patients have less access to pain management and are given fewer and less effective pain relievers than white, male patients. Women who are on Medicaid can be denied epidurals because of their cost, and modern anaesthesiologists freely invoke historic tropes about the 'worthy poor', arguing, 'Poor people can't expect to drive a Rolls-Royce... so why should they expect to receive the Cadillac of analgesia for free?"?

The origins of these debates are more than just partially rooted in the nearly simultaneous emergence of the Twilight Sleep and birth control movements. In pursuing the elimination of pain in the female reproductive life cycle, advocates sought to change the conversation about pain and its meaning for women and those arguments continue to have consequences today for the relationship between medicine and women patients. Activists argued that by eliminating the emotional fear and physical pangs surrounding childbirth, which contributed to women's social categorisation as inferior and unable to bear the duties of citizenship, it could bring women more fully into the public sphere. Indeed, examining how the emphasis on the elimination of women's pain within both the Twilight Sleep and birth control movements offers a new lens to understand the ways in which women activists restructured their political agency in the early 20 th century. At the heart of both movements was the idea that eliminating female reproductive pain and suffering was fully possible, and to do so had the radical potential to establish a new political order in which women were incorporated as equals. Considering the rhetoric of the two movements together sheds new light on the ways that women in the early 20th century thought about and conceptualised the elimination of the pain of reproduction both alongside and as part of the fulfilment of their political citizenship.
Advocating for better female health in general had been part and parcel of the feminist movement since its emergence in the 1840s. In the decades before the Civil War, the organised women's rights movement often adopted the same tenets of the broader health reform movements of the 20th century and tied the right to maintain good health to broader political rights. As The Woman's Journal put it, 'The advocates of Woman Suffrage generally attach quite as much importance to the health of women... and they have done as much as any class - by inquiry, physiological instruction and encouraging women to study medicine - to improve that health'. ${ }^{10}$ Activists argued that interventions like dietary changes, dress reform, temperance and the water cure helped women throw off their own subjugation to live a healthy and active life, a full member of the public sphere. ${ }^{11-14 i i}$ Much of the emphasis on health reform encompassed the right of women to control their sexuality and the number of children they bore. Proponents of 'voluntary motherhood' demanded that women choose when to have children within marriage to preserve their individual rights to their bodies. Alongside the concept of bodily autonomy, real medical fears animated these discussions over women, sex and health. Birth control was illegal under the Comstock laws which, alongside pornography, classified all contraceptive information and devices as 'obscene, lewd, or lascivious'. Fines for violating the law were steep, often equivalent to hundreds of thousands of dollars, which made even sympathetic physicians skittish when it came to discussing birth control with their patients. The difficulty of obtaining contraception in the late 19th and early 20th centuries made it nearly impossible for women to reliably or safely space their pregnancies.

Yet the voluntary motherhood philosophy did not initially include supporting artificial birth control. Women reformers argued that within the existing gender structure of Gilded Age society, contraception would simply have increased men's sexual freedoms while restricting their own. More important was the simple right of sexual refusal which, as historian Linda Gordon has observed, was 'a key substantive demand in the mid nineteenth century when both law and practice made sexual submission to her husband a woman's duty'. ${ }^{15}$ 16iii By 1915, however, activists like Margaret Sanger, Elizabeth Stuyvesant, Jessie Ashley and Mary Ware Dennett were urging public support for birth control as a key tenet of the voluntary motherhood philosophy. In Sanger's introductory missive 'To the Men and Women of the United States', in the first issue of her magazine The Birth Control Review, she wrote, 'The people are waking to the fact that there is no need to bring their children into the world haphazard, but that clean and harmless means known whereby children may come when they are desired, and not as helpless victims of blind chance'. ${ }^{17}$ For these reformers, 'children by choice and not chance' held the key to improving women's place in society and to elevating humanity.

The dangers of childbirth in the late 19th century animated this reasoning. Aside from death, other issues such as lacerations, tears in the vaginal wall or uterus, uterine prolapse, vesicovaginal fistulas, diastasis recti and other issues plagued women with irritation, incontinence, pain and often lifelong debilities. ${ }^{18}$ As both Jacqueline Wolf and Judith Walzer Leavitt have explored, women greatly 'feared [the] pain and suffering' that accompanied childbirth, describing their experiences as 'terrible', and

\footnotetext{
${ }^{\text {ii }}$ See for example refs. ${ }^{11-14}$

${ }^{i i i}$ For more on the relationship between social purity and voluntary motherhood, see Gordon. ${ }^{16}$
} 
with 'inconceivable agony'. ${ }^{18-22 \text { iv }}$ Suffragist and birth control reformer Mary Ware Dennett experienced three pregnancies and deliveries that resulted in these common, but serious, health problems. Carleton, her first son born in 1900, survived but required 'artificial feeding', as Dennett remained ill from the strain of labour and unable to breastfeed. ${ }^{23 \mathrm{v}}$ In 1903, the birth of her second son, Appleton, was equally traumatic, and he died at 3 weeks old of starvation. Their third child, Devon, was born healthy in 1905, but she had major complications from the birth that eventually required surgery. Physicians advised Dennett that another pregnancy would kill her and that she and her husband should completely abstain from sexual intercourse. Given the illegality of birth control, and their refusal to tell her how to use it, Dennett had little choice but to follow the recommendations of her physicians. She and her husband would ultimately divorce, after he sought the affections of another woman.

In the first half of the 19th century, some medical textbooks noted that childbirth pain was a 'natural function, so it ought not to be interfered with' and that to provide anaesthesia was akin to promoting drunkenness-an immoral act. ${ }^{24}$ By the late 19 th century, however, most physicians were cognizant of their particular role in alleviating women's pain during pregnancy and childbirth. St. Louis physician Dr I.N. Love told his fellow doctors at the 1893 American Medical Association's obstetrical section meeting that 'As physicians, we may well ask ourselves if we sufficiently appreciate the importance of saving our patient pain'. He noted that pain often was 'an announcement' that 'something is wrong and needs correction', and that methods to relieve it should be mostly conservative, lest the physician end up removing 'nature's flag of distress' rather than the actual cause. However, when it came to labour, his opinion, he told the audience, was that pain in parturition was unnecessary and harmful. ${ }^{25}$

When the medical intervention of Twilight Sleep, or the use of a scopolamine-morphine mixture to anaesthetise labouring women, was first developed in the early 20th century, it thus appeared to be an enormous technological leap in obstetrics. As scholar Amy Hairston has pointed out, the 'new use of an amnestic/narcotic mixture that induced twilight sleep represented one of the first tools that dramatically distinguished the scientific practices of the obstetricians from those of the midwives and GPs' (Hairston, 491). ${ }^{19}$ Scopolamine as an amnestic, or an agent that prompts memory loss, could be used by itself to allow labouring women's muscles to continue to do the work of childbirth, while prompting a state of semiconsciousness throughout. Combined with a narcotic like morphine, the mixture would also create an anaesthetic effect, even though it did not completely remove the pain of labour. However, the promise of assuaging the reproductive pain and suffering experienced by so many women was nothing short of revolutionary.

There were a few documented uses of scopolamine in birth in the first decade of the 20th century. In June 1914, two female journalists then brought news of the method to American women from Germany. Marguerite Tracy and Constance Leupp in a widely read article for McClure's Magazine described the experience of women using the miraculously 'pain-free' birth method of Dammerschlaf. ${ }^{26}$ Developed at the University of Baden at Freiburg by physicians Bernhard Krönig and Carl Gauss, Dammerschlaf consisted of an initial injection of a

\footnotetext{
${ }^{\text {iv }}$ Quoted in Leavitt (336). ${ }^{18}$ For other scholarly work on Twilight Sleep, see refs. ${ }^{19-22}$

${ }^{\mathrm{v}} \mathrm{See}$ Chen. ${ }^{23}$
}

scopolamine and morphine, but subsequent injections consisted only of the amnestic scopalamine. Tracy and Leupp wrote, 'The Twilight Sleep is a light sleep induced by an injection or two of a combination of two drugs - scopolamin and morphium.... It is a sleep so light and so susceptible to outside impressions that semi-darkness and quiet are required to make it entirely successful. The ordinary tests of consciousness cannot be applied to it. It is attained at a point when the patient loses the power of recollecting immediate events and sensations, while still remaining susceptible to suggestions, and in full possession of muscular powers (Tracy and Leupp, 39). ${ }^{26}$ The journalists also positioned Twilight Sleep as far safer than the use of forceps during labour and cited the low death statistics of infants born in the state of Baden whose mothers opted for the method.

Using phrases like 'humane forgetfulness', the essay described Twilight Sleep as an important development in reduction of childbirth pain, and one that would advance humanity. Tracey and Leupp urged women to share the news of the method widely, and argued that making Twilight Sleep widely available would overturn the ancient Biblical argument about women's duty to bear pain because of her sins. 'The rumor has gone out, from mouth to mouth, among women to the ends of the earth, that here, at last, modern science has abolished that primal sentence of the Scriptures on womankind: "In sorrow thou shalt bring forth children" '. (Tracy and Leupp, 38). ${ }^{26}$ For the story, the two journalists interviewed women who used the method during labour and described the hearty meals they were able to eat afterwards, the brisk walks they took and the general feeling of well-being that the women exhibited in the aftermath of the birth process.

In an October follow-up to the original article, Tracy and another journalist, Mary Boyd, wrote, 'No article ever published in McClure's attracted more attention than "Painless Childbirth" in the June issue'. ${ }^{27}$ In this second instalment on Twilight Sleep, they charged that obstetricians knew about the 'Freiburg method' but refused to implement it because it 'takes too much time, and in hospitals is too expensive'. The authors urged physicians to understand how revolutionary American women would find the method, writing 'Every woman actually confronted with an imminent birth is filled with a living fear of death that few men can grasp (Boyd and Tracy, 58). ${ }^{27}$ They argued that the painlessness of Twilight Sleep resulted in fewer dangers to the health of the labouring women and stronger, healthier babies.

The article in McClure's did indeed spur American women to action. On 20 January 1915, five hundred women, many already active in various other women's clubs and causes, attended a public meeting at the Hotel McAlpin in New York to organise a national Twilight Sleep Association (TSA). ${ }^{28}$ They envisioned themselves as a funding organisation that would work to establish teaching hospitals devoted to the Freiburg method, as well as a clearinghouse of information and a parent organisation for local affiliate groups throughout the USA. ${ }^{\text {vi }}$ Suffragist Mary Ware Dennett was elected first vice president. She and her fellow activists were adamant that the widespread implementation of the Twilight Sleep method in hospitals would revolutionise the notoriously dangerous and painful childbirth process for women. Distribution literature explained to women that Twilight Sleep

\footnotetext{
vi Pamphlet, Women's Studies Manuscript Collection, Series 3, Reel 31. See also TSA Executive Secretary to Elizabeth B. Nesbitt, 2 April 1915 Women's Studies Manuscript Collection Series 3, Reel 30.
} 
was the best solution for eliminating 'childbirth with its attendant agonies, horrors, [and] fears' for all women. ${ }^{\text {vi }}$

Representatives of the TSA staffed information booths at events, organised department store conferences, held local meetings at the homes of women who had experienced Twilight Sleep births already and sent speakers on a publicity tour. However, like the suffrage movement, not all women were supporters of the campaign. Some questioned the efficacy of the method, arguing that the drug might have unknown harmful effects. Mrs Elizabeth Curtis of the Civic League of Saginaw, Michigan, complained to the Journal of the American Medical Association in June of 1915 that a local exhibit and presentation on Twilight Sleep was nothing more than a 'misleading and harmful' 'commercial exploitation of maternity' and a direct attack on the medical profession. ${ }^{29}$ Curtis, part of the lay opposition to Twilight Sleep, joined a growing chorus of physicians who also objected to the fact that there was not enough evidence to prove the method's safety and efficacy.

To assuage these concerns, the TSA campaigned on a platform of having the full cooperation of physicians. Pursuing obstetrician involvement with zeal, the TSA noted 'our absolute dependence upon them in the final analysis for the accomplishment of our aim'. The executive secretary of the Association wrote to another reformer that 'An open teaching hospital - ideally equipped - in which the practice, its cost, etc. can be standardized, the method learned and thus carried through the United States is the only thing which can make Twilight Sleep permanent and universal'. viii The delicate drug protocol for the scopolamine-morphine mix necessitated precise dosages administered at precisely the right times, along with continuous checks on patients with 'memory tests', designed to ensure that the scopolamine was working. Yet the annual report of the TSA reported that often their efforts were met with resistance, and it did not take long for physicians to voice their opposition to the treatment. As early as 1914, Illinois physician John Salisbury argued that the McClure's article 'is a good example of the fallacious arguments and pictorial intimations that are being pressed on the American public in support of this very doubtful procedure in obstetrics'. Because Tracy, Leupp and Boyd alternately referred to it as both anaesthesia and an amnestic in order to suit their own purposes and better persuade their readers, he and others were able to immediately cast doubt on whether Twilight Sleep was actually a miracle for women as claimed. Salisbury urged the American Medical Association to take a stand against Twilight Sleep, pointing out that the method was 'not absence of pain but abolition of memory' and that this distinction was important. ${ }^{30}$

Still, the TSA castigated physicians' refusals to support the use of the Freiburg method and charged their reluctance as the utmost in professional laxity and ignorance. Imitating an unwilling doctor, the report read, 'No, thank you, we will proceed in the ancient way and as far as the Dammerschlaf is concerned, it was condemned a priori, because (a) we will never forgive the laity for having caught us napping; (b) the method is too much work for us - good for the mothers, oh yes, but it does not expedite our work.... ${ }^{28}$ Yet the women writing and crusading for Twilight Sleep continued to insist on the need for male physicians' cooperation. A membership dues card summarised the debate thus:

\footnotetext{
vii Pamphlet, Women's Studies Manuscript Collection, Series 3, Reel 31. viiiTSA Executive Secretary to Elizabeth B. Nesbitt, 2 April 1915. Women's Studies Manuscript Collection Series 3, Reel 30.
}

Sir James Young Simpson, the discoverer of chloroform, pointed out that in the only case of male parturition on record: 'The Lord God caused a deep sleep to fall upon Adam' (Genesis: 2:21). Marguerite Tracy points out that medical science of today has put Twilight Sleep at the service of women, but that as the Lord God also said 'Thy husband shall rule over thee' (Genesis 3:16), it is clearly the duty of man to lift Eve's age-long curse.

Similar to tactics used in the suffrage movement, women reformers urging the adoption of Twilight Sleep cited the need for male expertise and approval in order to efficiently advance their end goals.

Twilight Sleep also fit neatly into the progressive milieu. Progressivism promised to solve the problems wrought by industrialism and capitalism-immigration, crime, degeneracy and disease, and housed a diverse set of initiatives within its broad ideology of social improvement. ${ }^{31-33}$ Eugenics, the science of improving humanity developed by British researcher Francis Galton, was one of those initiatives that held broad appeal for all strands of progressive ideology. Originating from the Greek word meaning 'good in birth' eugenics was malleable, useful for promoting both 'positive eugenics' (encouraging the best people in society to have more children) as well as 'negative eugenics' (restricting the reproduction of those deemed unworthy) (Kline, 13). ${ }^{31}$ Although eugenics began as a broad movement that encompassed different ideas for how it could improve humanity and elevate the status of women, by the early 1920s the movement's emphasis on restrictive reproduction allowed for the proliferation of sterilisation laws and immigration restrictions designed preserve the purity of the white and native-born American race.

The mostly middle and upper class, white clubwomen crusading for Twilight Sleep at first presented the method as a boon for all classes of mothers. The first annual report of the Association stated that 'constant letters of inquiry showed an intense interest in every part of the country among women of all classes but particularly among the poor and those of moderate means - the great childbearers of the world'. ${ }^{28}$ However, reformers also argued that upper-class women's fear of childbirth pain was preventing them from having enough children to sustain the health and wealth of the nation ${ }^{\text {ix }}$ (Wolf, 17). ${ }^{21}$ President Theodore insisted that white women's reluctance to have children shirked their patriotic duty and constituted nothing less than 'race suicide'. ${ }^{\mathrm{x}}$ The usage of the phrase 'race suicide' and discussion surrounding 'the race' were both ambiguous and specific. As Diane Paul has noted, referring to 'race hygiene', 'racial efficiency', 'racial vigour', 'race death' or suicide and 'race decadence' were terms that encompassed a variety of meanings in the early eugenics movement. ${ }^{34}$ These terms could simultaneously allude to racial classifications and the need for whites to have more children, as well as differences in ethnic groups and the broader progress of humanity in general. These capacious meanings therefore allowed Twilight Sleep's proponents to argue effectively that the method was an excellent solution for assuaging mother's fears and increasing the birth rate. ${ }^{35}$ With the miraculous advent of 'painless childbirth', women could enthusiastically resume their fertility without fear and produce more and 'better babies'. Physician Bertha Van Hoosen argued

\footnotetext{
${ }^{\mathrm{ix}}$ Jacqueline Wolf notes that the birth rate between 1800 and 1900 for white women of childbearing age fell from 7.04 to 3.56.

${ }^{\mathrm{x}}$ Address by President Roosevelt before the National Congress of Mothers. Theodore Roosevelt Collection. MS Am 1541 (315). Harvard College Library.
} 
that Twilight Sleep's positive eugenic influence thus had the potential to solve the social problems of 'prostitution, abortions, divorces, unwilling motherhood.... and [venereal disease]' (Wolf, 54). ${ }^{21}$ Proponents argued that the modern woman could now give birth the same way as the lower classes who, like Krönig's 'gypsy nature-woman', were presumed to 'drop' children with ease and need little recovery time. ${ }^{36}$ Linking strength and health with both race and class, the Twilight Sleep method would help the 'right' kind of women birth more children, more easily.

It is not surprising that the Twilight Sleep method exploded in popularity. Between 1914 and 1915, numerous hospitals around the USA implemented the Freiburg method. Upper and middle-class patients who could afford to pay for the method often ignored the safety issues surrounding Twilight Sleep in favour of eliminating the memory of the accompanying pain and effort of labour. There were, of course, serious medical concerns about using the scopalamine-morphine mix and its effects. It often delayed or made labour longer, gave women postpartum headaches or induced violent states of delirium, necessitating them to be confined to their beds with canvas cages. Despite the amnesia-inducing scopalamine, many patients retained 'memory islands', wherein the drug's instability often prompted them to remember their pain as well as the excessive thirst, blurred vision and intense postdelivery headaches that accompanied the procedure. One year-long medical study of patients conducted at Michael Reese Hospital in Chicago concluded that Twilight Sleep did not, in fact, eliminate 'the horrors of the delivery room'. Describing the treatment as full of 'violence and uncertainty' the physicians in charge wrote, 'we feel compelled to condemn' Twilight Sleep. ${ }^{37}$

However, other doctors disagreed whether the method had deleterious effects. Dr John Osborn Polak, professor of obstetrics and gynaecology at Long Island College Hospital in New York, claimed in his own study of 400 patients that there had been 'no maternal mortality' and 'no child has been born dead' under his care. Although some doctors contended that women were not entitled to pain relief during childbirth since 'labor is a physiologic process', Polak disagreed, arguing, 'physiologic acts are better and more easily performed when one is insensible to physical pain'. He concluded that Twilight Sleep had a 'distinct place in hospital obstetrics, ${ }^{38}$

Despite the national campaign of the TSA and the optimism of doctors like Polak, the practice came under significant fire from most of the American medical profession by the end of the decade. Noticeable problems with dosage and monitoring caused hospitals and physicians to largely abandon the practice. By 1918, physician Edward Davis, professor of obstetrics at Philadelphia's Jefferson Medical College, concluded, 'The combination of the treatment by suggestion, discipline, morphin and scopalamine, known as the twilight sleep method, has largely collapsed, ${ }^{39}$ Although scopalamine continued to be part of obstetrical practice until the middle of the twentieth century, it was never routinely available to all labouring patients.

Historian Judith Leavitt has argued that the short-lived advocacy for Twilight Sleep was a study in contradiction. On the one hand, the initial agitation for Twilight Sleep rested in women's desire for choice and was a natural extension of the broader women's rights movement. Demanding to make their own decisions about childbirth was part of the much longer history of women's management of their own reproduction in American history. The Twilight Sleep movement was part of this tradition and gained the traction that it did precisely because, even as late as the World War I era, the majority of births were not taking place in hospitals or with physician attendance. For a brief point in time, the movement's insistence on involving doctors and hospitals in women's labours seemed to be a revolutionary approach - a new choice for childbirth previously unavailable. ${ }^{40}$ Their rhetoric also emphasised the politics of a pain-free body and the connection between a woman's health with her rights to citizenship. Charlotte Teller, in an article for Good Housekeeping on 'The Neglected Psychology of Twilight Sleep', argued that the concept of women's bodies as functioning 'not as instruments of cosmic forces, but as the personal possessions of ourselves' echoed long-standing arguments from the women's movement that had stressed the autonomy of the female body in a world subject to male control. For Teller, who invoked the emergent discipline of psychoanalysis to explain the impact of pain on women's' well-being, the promise of Twilight Sleep's elimination of the memory of labour pain was that it helped to erase 'terrific conflict between the women's lifelong sense of belonging... to herself, and her realization that she is losing this identity in surrendering to the unknown' (Teller, 18). ${ }^{8}$

Unfortunately, the agitation for Twilight Sleep as a medicalised intervention ultimately failed the women's movement's drive for better reproductive health and autonomy. The American medical profession successfully rejected the idea that a female public should decide what kinds of treatment were safe. The "high society framing' of Twilight Sleep in the media and its support by wealthy, upper-middle class clubwomen produced 'pointed public interest' in the method and encouraged its initial popularity in usage, but ultimately allowed physicians to frame them as mere socialites with a 'faddish preoccupation'. ${ }^{41} 42 \times \mathrm{i}$ They easily condemned the women's lack of knowledge around terminology and procedure and declared that this ignorance made them unfit to weigh in on the discussion of labour methods.

Moreover, the specialty of obstetrics, one previously scorned by many in medicine as requiring little training and attracting the poorest medical students, gained enormous respect since the protocol for Twilight Sleep required such precise calibration. In addition to further discrediting midwives in favour of trained expert physicians and professional hospitals, ultimately, it was, as Leavitt notes, 'The medical profession [who] retained the choice of birth procedures and perhaps gained additional control as a result of this episode.... Ironically, by encouraging women to go to sleep during their deliveries, the twilight sleep movement helped to distance women from their bodies. [The] movement helped change the definition of birthing from a natural home event... to an illness requiring hospitalization and physician attendance ${ }^{43}$ For the rest of the 20th century, most women gave birth in hospitals under the supervision of doctors who turned to other drug combinations to ease women's labour experiences.

Nevertheless, even as Twilight Sleep itself was ultimately discredited as a childbirth intervention, the publicity surrounding its development did have important ramifications for the broader progressive campaign to advance women's and children's health. Activists successfully pushed 'to the center of the stage the question of control in the birthing process' (Pitcock and Clark, 584). ${ }^{20}$ The experience of advocating for the Freiburg method encouraged women reformers to continue to question physician authority and to emphasise the medical duty to alleviate pain. Moreover, the broader social emphasis on maternal and child health wrought significant policy changes at the federal level.

${ }^{\mathrm{xi}}$ See also Johnson and Quinlan. ${ }^{42}$ 
The Sheppard-Towner Act, or the Promotion of the Welfare and Hygiene of Maternity and Infancy Act, was passed in 1921 and signed into law by President Warren G Harding. The act, sponsored by the federal Children's Bureau and endorsed by numerous women's groups, provided government aid over a 5 -year period to enact prenatal and newborn care programming throughout the USA. Although the programme was discontinued in the 1930s after the onset of the Great Depression, the funding particularly aided women, infants and children in rural areas and contributed to a significant decline in the infant mortality rate by the late $1920 \mathrm{~s}^{44}$

In the emergent birth control movement, reformers pointed out the folly of not including legal contraception within these broader maternal health initiatives. Sanger wrote, 'The educational work of the Children's Bureau, under the Sheppard-Towner Act will lack the prime essential until preconceptual work - Birth Control - is added to its educational program... until [we] unite to change our anti-Birth control laws... the system of maternity and infant care... will be far short of its usefulness' ${ }^{45}$ Dennett also noted the hypocrisy of those who supported the passage of the Sheppard-Towner Act but not the legalisation of birth control. She argued for an understanding that birth control was 'the very basis of child welfare' and that the 'service' provided by the proposed Sheppard-Towner Act would be 'incomplete' without teaching women how to 'space births by regulating conception'. ${ }^{46}$

Dennett, after volunteering for the TSA, also founded the National Birth Control League in 1915-the first birth control organisation in the USA (and later renamed the Voluntary Parenthood League). She insisted from the beginning that doctors had a responsibility to their patients to give them proper, scientifically based contraceptive information and that only the law prevented them from doing so legally. These arguments also emphasised that preventing women's physical (and related psychological) pain was at the heart of legalising birth control. An early League pamphlet emphasised that one of contraception's chief aims should be 'the preservation of women from too frequent pregnancy (which leads to a shattered, nervous and physical condition, both in mother and child) ${ }^{47}$ Likewise, Margaret Sanger, who established the American Birth Control League in 1921, noted her horror at the 'sheer human waste' wrought by the high maternal mortality rate and insisted that only legal birth control could help eliminate the problem. She wrote in one editorial that 'more women die in childbirth in the United States than in any other country in the world... there is no moral excuse'. ${ }^{48}$

Women themselves in their letters to both Sanger and Dennett spoke of their need for contraceptive information to fix the pain they were experiencing in the aftermath of labour and during the drudgery of childrearing. Women described a litany of issues in Dennett's Birth Control Herald, including heart trouble, severe backaches and haemorrhaging and highlighted their constant exhaustion and weakness. One correspondent lamented, 'It isn't right that [the children] have to have a wreck of a mother who is always too tired to give them time for pleasure'. ${ }^{49}$ Another, writing to Margaret Sanger, fretted that both she and her baby were weak and sick. She wrote, I lost my oldest at 14 months old, and I don't believe my baby will live that long. I dearly love children, but I don't believe it is right to bring little diseased children into the world to suffer and die, beside I am very weak and don't think I can stand to have many more'. ${ }^{50}$ These women's missives clearly connected the experience of pain to their desire to eliminate it through the application of birth control. Sanger summarised their points as 'We want mothers to be fit... We want them to carry their babies during the nine months in a sound and health body... It is almost impossible to imagine the suffering caused to women, the mental agony they endure, when their days and nights are haunted by the fear of an undesired pregnancy'. 51

Implicit in this argument was that women could not participate fully in society, haunted as they were by anxiety and the experience of real physical pain during labour and after. Their narratives of pain and the desire to get rid of it revealed a marked shift in understanding of what women's pain signified for their political place. No longer did their sufferings in maternity and childbirth fulfil a redemptive purpose and fulfil the biblical notion of the necessity of women's' suffering. Instead they noted their desire for a healthy and fulfilling existence, free of pain and distress.

Like the Twilight Sleep movement, Dennett and Sanger's activism situated the need for legal birth control within eugenic arguments directed at overall public health and improvement of the human condition. Organisations like the League of Women Voters, who had supported measures like Twilight Sleep and the Sheppard-Towner Act, also debated the value of supporting birth control as part of their other health reforms. For example, one League draft report argued that there should be 'a measure or law that would allow the establishment of public clinics for the dissemination of information to married people, concerning contraceptives, and the repeal of such laws which make the giving of such information a felony'. The committee commented,

We realize that there is much opposition to this work and that the efforts of Mrs. Margaret Sanger seem to have been fruitless and followed by prison sentences; but at least she has called the attention of the public to the need of such work. Perhaps this is not the correct way or the best way to prevent compulsory motherhood but one has only to stop and think of the poor mothers, who are worn out before their time with the bearing and caring of too many children, to realize there must be something done... Surely the nation and the race would be better off with fewer, better, and healthier babies, and women happier and of more service to the community if not so often, compulsory mothers. ${ }^{\text {xii }}$

This report also simultaneously recommended that League women attorneys in each state agitate for legislative passage of marriage restrictions 'in the interest of eugenics', as well as lobby for laws 'providing for the sterilization of defectives and epileptics'. Despite the League committee's initial support for including birth control as a key reform, subsequent drafts of the report then struck out the paragraphs concerning birth control, leaving only the recommendations on sterilization. The final statement read, 'Law should provide for the sterilization of defectives and epileptics by the state, so they would be prevented from reproducing their kind, to become a burden on the state in after years' ${ }^{52 x i i i}$ This version was then published in the League newsletter, The Woman Citizen. ${ }^{53}$ The League of Women voters continued to focus its energies on Progressive 'social hygiene' measures, including encouraging state legislature to adopt antiprostitution measures, venereal disease ordinances and laws governing 'delinquents, minors, and defectives'. ${ }^{54}$ Women

\footnotetext{
xii Undated report, Catharine Waugh McCulloch Papers, Series VI of the Mary Earhart Dillon Collection, 1869-1945, Schlesinger Library, Radcliffe Institute, Harvard University.

xiii Undated report, Catharine Waugh McCulloch Papers, Dillon Collection, Schlesinger Library. As Edward Larson has shown, federated women's clubs (particularly in the South) were instrumental in lobbying state legislatures to establish public institutions for the eugenically unfit.
} 
reformers insisted that the Constitution guaranteed 'equal rights and equal privileges' and the 'equal opportunity for health.' For many, this meant the restriction of others' rights in the name of improving public health. ${ }^{55}$

By the mid-1920s, Margaret Sanger also recognised the utility of fitting birth control into this same eugenic framework and would, against Dennett's urging, successfully argue for contraception to take its place in the larger programme of population control and restriction of the reproduction of the 'unfit'. ${ }^{56}$ She and other crusaders like Havelock Ellis argued that birth control was a valuable new weapon for 'the white stock' whose 'racial vitality' was being sapped by 'influences of previously unknown virulence'. Contraceptive knowledge and use needed to be disseminated downwards to the 'lower classes' so they could begin using it. Ellis remarked, "We begin... to discern that by the judicious use of the instrument of birth control, in light of an ever-growing knowledge of the eugenic aspects of heredity, it is possible... to cut-off the supply of the unfortunate and to diminish steadily the output of incapables... we have struggled vainly to stem the tide of unfit babies, and now at last we have learnt the magic formula to apply at the source'. ${ }^{57}$

Although Dennett also courted the support of eugenicists in the campaign, she was against the idea of employing birth control for eugenic uses. She considered the issues of birth control and eugenics 'as almost entirely separate', not to be 'jumbled' as 'two quite different considerations... They are far from synonymous'. She abhorred arguments that equated eugenics and birth control that advocated for 'the control of the unfit as if were simple birth control problems, when they actually have to do with sterilization and segregation and various forms of governmental functioning by which the freedom of the individual is curtailed for the good of society ${ }^{58}$ She was especially scornful of Sanger and other 'neo-Malthusian' alarmist positions that advocated that birth control was the only hope for saving the 'less prolific, highly civilized, more fit white skinned peoples' from the 'more prolific, undeveloped, unfit and darkskinned peoples'. ${ }^{59 x i v}$ Whereas Twilight Sleep had been part of a positive eugenic framing, encouraging the better classes to have more and better babies, Sanger and other reformers pointed to birth control as another negative eugenic method to restrict the lower classes from overbreeding. The making of the explicit connection between eugenics and birth control deradicalised the movement's origins as rooted in women's rights and the philosophy of feminism, and instead popularised it by touting it as method of social control that would reduce the breeding of the 'unfit'. The definition of 'unfit' could then be defined as broadly or as narrowly as needed. Today's fierce debates over the role of federal funding for contraception and abortion reflect the complex history of both these historic linkages and severed connections between eugenics, birth control and women's place in society.

Yet like Twilight Sleep, whose ultimate goal was the broader reduction of pain and suffering, it is important to note that

\footnotetext{
xiv'Birth Control, War, and Population' unpublished essay, Mary Ware Dennett Papers, Schlesinger Library. Lynn Lederer's PhD dissertation also argues that Dennett held antieugenic stances, noting 'Dennett, however, did not support eugenics and never resorted to using eugenics doctrine to support birth control. Although surrounded by eugenicists, her message remained firm, grounded in the belief that everyone had the right to know, to know about birth control, to know about sex, and then to make their own decision. Dennett framed her support for birth control devices and information as a fight for liberty, rather than a fight for social welfare' (83).
}

linking birth control with negative eugenic philosophy was only part of Sanger's strategy to legalise it. She also never abandoned her other focus on the idea that the contraception's illegality increased women's physical and psychological suffering. Sanger spoke of children's 'right to be wanted' and editorialised, 'As mothers of future generations we must show our interest in the coming race by doing everything in our power to ensure each child that is born, a welcome and the fundamental right to health and the possibility of happiness'. As early as 1919, she asked in the Birth Control Review, 'Is Birth Control a Constitutional Right?' She noted the 'oppressive' statutes of the Comstock obscenity laws that 'violated the legal as well as natural rights of women' and lamented the fact that the courts continued to leave 'this question, the most momentous for women that ever arose in the Supreme Court of the United States...undecided ${ }^{60}$

In Dennett's case, she had also learnt much from watching the interplay between reformers and physicians during the heyday of Twilight Sleep. When it came to contraception, she warned against the patriarchal nature of physician monopolies, arguing 'The function of the medical profession is to cure and prevent disease. It is not to act as arbiter of morals and ethics.... Laws that would try to empower physicians to act as inquisitors into the private lives of their patients and to be responsible for the ethical use of contraceptive instructions, would be an imposition both upon the physicians and upon the people'. ${ }^{61}$ She viewed birth control as a necessary part of regular medical treatment and condemned doctors who made moral judgements on its use and efficacy. Indeed, Dennett's early emphasis on physician ethics and the debates over preserving patient privacy versus public morality are highly resonant in the present day as modern medicine continues to grapple with issues present in patient-centred care. Particularly in the realm of obstetrics and reproductive healthcare, doctors must negotiate between their own professional autonomy and the autonomy of their patients. ${ }^{62}$ Dennett's identification of the need for physicians and patients to engage in shared decision making over the birth process and the prevention of pregnancy predated the broad shifts that would then occur in medical ethics beginning later in the 20th century.

Moreover, Sanger and Dennett's canny framings of birth control as part of larger maternal care issues were designed to foster sympathy for the movement and had the effect of incorporating women's reproductive pain, both emotional and physical, into broader understandings of the ways that women's rights were circumscribed by their procreative capacity. Although the two women had marked ideological disagreements over the best approach to legalising contraception, both Dennett and Sanger's attitudes about pain were part of a longer tradition in the feminist movement of championing women's right to good health. Both women understood the radical potential of the ability to control reproduction in altering women's place. They argued that the elimination of reproductive pain through the twinned remedies of anaesthesia and legal birth control would allow women to assume the duties of citizenship in ways that had been previously impossible. Freedom from the fear surrounding childbirth was nothing less than the elimination of tyranny. ${ }^{17}$ Reformers active in both movements framed pain as a medical problem that could be solved through technology and expertise, and as a human advancement that was part of a broader political reckoning over the place of women in public life. The shared goals within the movements for Twilight Sleep and birth control had broad significance for the discipline of medicine and for the larger advancement of women's legal rights in the first decades of the 20th century. Today, their legacy continues in medicine's ongoing 
negotiations with patients over choice in reproductive healthcare and pain management policy.

Funding The authors have not declared a specific grant for this research from any funding agency in the public, commercial or not-for-profit sectors.

Competing interests None declared.

Patient consent Not required.

Provenance and peer review Not commissioned; externally peer reviewed.

\section{REFERENCES}

1 Stanton EC. Address at the decade meeting, on marriage and divorce. Davis PW, ed. A history of the national woman's rights movement for twenty years: with the proceedings of the decade meeting held at Apollo Hall, October 20, 1870, from 1850 to 1870. 1871. New York: Journeymen Printers' Co-operative Association:59-83.

2 Morosco J. Pain: a cultural history. UK: Palgrave Macmillan, 2012.

3 Morris DB. The culture of pain. Berkeley: University of California Press, 1992.

4 Pernick MS. A calculus of suffering: pain, professionalism, and anesthesia in nineteenth-century America. New York: Columbia University Press, 1985.

5 Rey R. The history of pain. Cambridge: Harvard University Press, 1995.

6 Roberts D. Killing the black body: race, reproduction, and the meaning of liberty. New York: Knopf Doubleday, 2014.

7 Cooper Owens D. Medical bondage: race, gender, and the origins of American gynecology. Athens: University of Georgia Press, 2017.

8 Teller C. The neglected psychology of twilight sleep. Good housekeeping. 1915;41:23.

9 Bourke J. The story of pain: from prayer to painkillers. Oxford, UK: Oxford University Press, 2014:295.

10 The woman's journal, 1881;12:33.

11 Cayleff S. Wash and be healed: the water cure movement and women's health. Philadelphia: Temple University Press, 1987.

12 Kesselman A. The "Freedom Suit": feminism and dress reform in the United States, 1848-1875. Gender and Society 1991;5:495-510.

13 Morantz RM. Making women modern: middle class women and health reform in 19th century America. J Soc Hist 1977; 10:490-507.

14 Vertinsky P. The eternally wounded woman: women, doctors, and exercise in the late nineteenth century. New York: St Martin's, 1990.

15 Gordon L. Voluntary motherhood: the beginnings of feminist birth control ideas in the United States. In: Leavitt JW, ed. Women and health in America. 2nd edn. Madison: University of Wisconsin, 1999:253-68.

16 Gordon L. The moral property of women: a history of birth control politics in America. Illinois: University of Illinois Press, 2002:72-85.

17 Birth control review February, 1917.

18 Leavitt JW. Under the shadow of maternity: American women's responses to death and debility fears in nineteenth-century childbirth. In: Leavitt JW, ed. Women and health in America. 2nd edn. Madison: University of Wisconsin, 1999:333-4.

19 Hairston AMYH. The debate over twilight sleep: women influencing their medicine. J Womens Health 1996;5:489-99.

20 Pitcock CD, Clark RB. From fanny to fernand: the development of consumerism in pain control during the birth process. Am J Obstet Gynecol 1992;167:581-7.

21 Wolf JH. Deliver me from pain: anesthesia and birth in America. Baltimore: Johns Hopkins University Press, 2011.

22 Sandelowski M. Pain, pleasure, and American childbirth: from the twilight sleep to the read method, 1914-1960. Connecticut: Greenwood Press, 1984.

23 Chen CM. The sex side of life: Mary Ware Dennett's pioneering battle for birth control and sex education. New York: New Press, 1996:49.

24 Gream GT. Misapplication of anesthesia in childbirth exemplified by facts. London: John Churchill, 1849.

25 Love IN. Relief from pain in labor. JAMA 1893;21:311-2.

26 Tracy M, Leupp C. Painless childbirth. McClure's Magazine. , 1914:43, 37-51.

27 Boyd M, Tracy M. More about painless childbirth. McClure's Magazine., 1914:43, 56-69.
28 Report of the Executive Secretary of the Twilight Sleep Association, 20 January1915-1 November 1915. Schlesinger Library, Women's Studies Manuscript Collection, Series 3, Reel 30.

29 Curtis ES. A 'twilight sleep exhibit.'. JAMA 1915;26:2157.

30 Salisbury JH. The twilight sleep in obstetrics. JAMA 1914;16:1410.

31 Kline W. Building a better race: gender, sexuality, and eugenics from the turn of the century to the baby boom. Berkeley: University of California Press, 2005:13.

32 Rodgers DT. In search of progressivism. Rev Am Hist 1982;10:113-32.

33 Stern AM. Eugenic nation: faults and frontiers of better breeding in modern America. Berkeley: University of California Press, 2015:31.

34 Paul DB. Controlling human heredity, 1865-present. New Jersey: Humanities Press, 1995:106.

35 Hellman AM. Amnesia and analgesia in parturition: twilight sleep: Hoeber, 1915:131.

36 Manton WP. Obstetrics. Pennsylvania: Lea \& Febiger, 1903:224.

37 Baer JL. Scopolamin-morphin treatment in labor: a critical analysis of sixty cases. JAMA 1915:21:1723-8.

38 Polak JO. Morphin and scopolamin amnesia in obstetrics. JAMA 1915;12:994-8.

39 Davis EP. Obstetric science and art in the service of the nation. JAMA 1918;71:1869.

40 Leavitt JW. Brought to bed: childbearing in America, 1750 to 1950. Oxford, UK: Oxford University Press, 1986:137.

41 Johnson B, Quinlan MM. High-society framing: the brooklyn eagle and the popularity of twilight sleep in Brooklyn. Health Commun 2017;32:60-71.

42 Johnson B, Quinlan MM. Technical versus public spheres: a feminist analysis of women's rhetoric in the twilight sleep debates of 1914-1916. Health Commun 2015;30:1076-88.

43 Leavitt JW. Birthing and anesthesia: the debate over twilight sleep. Signs 1980:6:147-64.

44 Centers for Disease Control. Figure 1: infant mortality rate, by year-United States, 1915-1997. MMWR Weekly 1999;48:849-58.

45 Birth control review, 1927.

46 Mary Ware Dennett to Nina D. Hess, 26 April 1921. Massachusetts: Mary Ware Dennett Papers, Schlesinger Library, Harvard University.

47 An endorsement of voluntary parenthood. Pamphlet, Madeline McDowell Breckinridge Papers, 1867, 1888-1923, 52M3, special collections. Lexington: University of Kentucky.

48 Birth control review, 1921.

49 The birth control herald, 1924.

50 Birth control review, 1922.

51 Sanger M. The case for birth control. In: Johnsen JE, ed. Selected articles on birth control. New York: The H.W. Wilson Company, 1925:134.

52 Larson EJ. "In the finest, most womanly way": women in the Southern eugenics movement. Am J Leg Hist 1995;39:119-47.

53 Stevenson FJ. Marriage and divorce. Woman's Journal 1920; 45;

54 Trumpet call to action from the Social Hygiene Committee of the National Leagues of Women Voters. Woman's Journal 1920;4:1256-61.

55 Johnson-Wood HM. Eugenics from a legal standpoint. Women Lawyers' Journal 1916:5:66-71.

56 Dikotter F. Race culture: recent perspectives on the history of eugenics. Am Hist Rev 1998:103:467-8.

57 Ellis H, Essays F. Four essays pamphlet, special collections, New York Historical Society. Girard, Kansas: Appeal Publishing Company, 1922.

58 Mary Ware Dennett to Sherwood Eddy, 1 June 1928, Mary Ware Dennett Papers, Schlesinger Library.

59 Lederer L. The dynamic side of life - the emergence of Mary Coffin Ware Dennett as a radical sex educator [PhD Dissertation: Rutgers, The State University of New Jersey, 2011.

60 Birth control review, 1919.

61 Dennett MW. Birth control laws, shall we keep them, change them, or abolish them New York: F. H. Hitchcock, 1926:239

62 Diamond-Brown L. "It can be challenging, it can be scary, it can be gratifying": Obstetricians' narratives of negotiating patient choice, clinical experience, and standards of care in decision-making. Soc Sci Med 2018;205:48 -54 